SIMULATED INTERACTIVE MANAGEMENT SERIES

\title{
Managing change in the emergency department: a personal view
}

E Seow

Emerg Med J 2004;21:71-74

This is a contribution to the occasional series on simulated interactive management

"Tell them that change is never over." Jack Welch ${ }^{1}$

$\mathrm{T}$ he emergency department (ED) of Tan Tock Seng Hospital has experienced three different organisational structures over the past 10 years. The aims of this article are to explore the strengths and weaknesses of these structures and present an opinion on the structure that best suits the challenges of an ED. We have experienced a "silo style" with completely separate management for nursing, medical, and administrative staff, a "matrix style" with a mix of accountability, and a "unified" structure. The multidisciplinary team is such an integral part of an ED structure that it is surprising that anything other than unified management should be considered. However, with the partial fragmentation of emergency medicine (EM) into its component parts with the introduction of nurse led minor injury streams, clinical decision units, and resuscitation there may be a threat to break with financial and managerial accountability of a single unified managerial structure. For those who may be faced with such challenges, I hope this will rehearse the arguments to keep the ED as a single management unit within your organisation.

"Working as part of a team is an integral part of A\&E medicine" and "many of the management decisions and tasks need the support and ideas from the team to have the best chance of a good outcome." ${ }^{2}$

\section{BACKGROUND}

Tan Tock Seng Hospital is a 1000 bed urban general hospital. It obtains funding from the government as well as from fees collected for services. The departments are designated as cost centres and the heads of service are expected to manage their department's budget. Eighty per cent of this hospital's admissions is through its ED. At the time of this article, it is the busiest ED in Singapore and had a census of 131127 in 2002.

\section{INITIAL ORGANISATIONAL STRUCTURE}

All EDs in Singapore started with a "silo style" management-that is, two or more separate reporting lines. In our case, the medical staff reported in hierarchical fashion to a clinician who was the head of the department. He in turn reported to the chairman, medical board (or medical directorate equivalent.) This line of reporting, or "silo", has its own budget, which included doctors' salaries and other remuneration.

In a similar fashion the nursing staff reported to the chief nurse in the department who in turn reported to the director of nursing. This "nursing silo" also had its own budget, which included the salaries of nursing and paramedical staff, and the operating budget of the ED as well (see fig 1).

"Silo style" management will work if there are no changes in the environment or strong personalities. Indeed a key strength is that it maintains the status quo.

In this initial organisation structure, our clinical head of ED had no direct control over the expenditure of the ED. The director of nursing (who had the final say on expenditures in the ED) was able to divert funds meant for ED to other departments under her control. In our case, ED funds were diverted to buy equipment for other departments as well as hire nursing staff for another area.

In managing an ED, it is important to remember that "the control of finance is a key part of the A\&E manager's role." ${ }^{\prime 3}$

There is no incentive for the personnel in these two "silos" to work with each other. This was well illustrated in our case when a group of nurses who did not agree with a patient care decision made by doctors (and agreed to by the ED chief nurse) complained to the director of nursing. She then "played politics" and the issue had to be resolved by the chief executive officer (CEO). Box 1 lists the SWOT analysis for this organisational structure.

\section{INTERMEDIATE ORGANISATIONAL STRUCTURE}

The change from the initial to the intermediate organisational structure occurred over a few years. In the beginning, the medical staff were quite happy to do medical work and leave nursing and operational issues to the nurses but we found that patient care improved tremendously when there was collaboration between the two groups.

The power of influence was very important in nursing accepting medical opinion. When the nursing leadership in the ED realised that we wanted to collaborate with them to improve patient care, their anxieties were allayed. Our opinions were sought more often just as we 


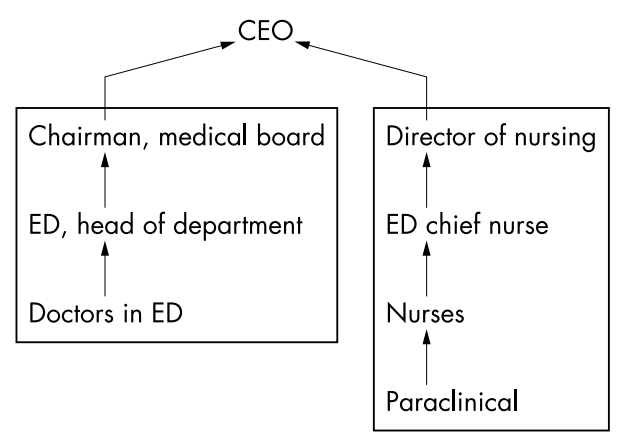

Figure 1 Initial organisational structure (silo style management).

would seek their views whenever we wanted to make changes. When ED nursing and medical worked closely on a daily basis, joint decisions on patient care are easily made. The power of influence should not be underestimated.

The capacity to influence the behaviour of another person is power.

French and Ravel, ${ }^{4}$ acknowledged as authorities on the subject of power within organisations, had postulated five bases of power:

1. Coercive power, which is based on fear and derived from the manager's ability to mete out punishment.

2. Reward power, which is the opposite of coercive power and is derived from the manager's ability to hand out rewards.

3. Expert power, which is derived from the manager's superior knowledge and access to information, which subordinates do not have.

4. Legitimate or position power, which is derived from the manager's more senior position or rank over the subordinate. This is conferred by the organisation's hierarchy.

5. Referrant (sometimes referred to as charismatic) power, which develops out of the subordinates' admiration for the manager, and their desire to model their own behaviour and attitude after the manager.

In the intermediate structure, most influence was attributable to expert power and a small portion from referrant power.

We had also begun to take an active interest in the professional development of our nursing colleagues. In-house training programmes were developed and conducted by the medical staff. Medical staff also raised funds to sponsor external educational courses for nurses. This is an example of the use of reward power.

When the "matrix style" of reporting (intermediate organisational structure) was introduced, it reflected the increased cooperation between staff groups in everyday work. This structure had the ED chief nurse reporting to both the head of department and the director of nursing (fig 2).

In our experience, whenever the director of nursing was new, there would be no interference with ED operations but when she was more settled, she would fail to cooperate fully and resist the development of the ED. It is important that ED doctors and nurses recognise "political play". After all, "management is about people and knowing the "movers and shakers" in your organisation is one of the first steps in departmental leadership."

One problem that we encountered with this matrix reporting system was that operational decisions could not be made in a timely fashion, for example, we were short of nurses but the director of nursing would not agree to ED
Box 1 SWOT analysis for the initial

organisational structure

Strength

- line of reporting is very clean

Weakness

- staff would hesitate to multitask

- the line of work was clearly drawn

- difficult to build a team

\section{Opportunity}

- each group could grow at its own pace

\section{Threat}

- one group's growth could outstrip others by miles and this can lead to frustrations within each group and friction between the groups.

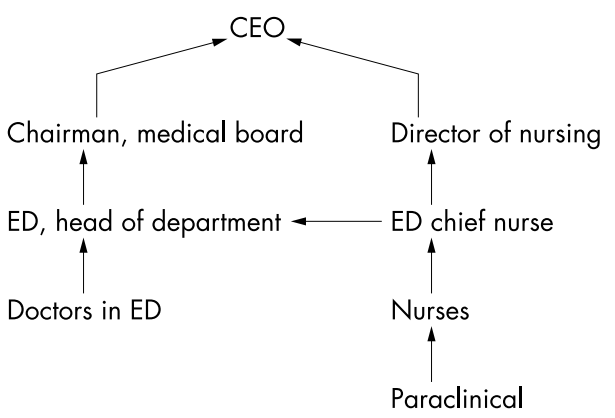

Figure 2 Intermediate organisational structure (matrix style management).

hiring agency nurses although ED had the funds. Box 2 lists the SWOT analysis of this intermediate organisational structure.

\section{PRESENT ORGANISATIONAL STRUCTURE ("'BUSINESS UNIT CENTRE")}

The present structure is that of a business unit centre where all staff reported to the head of department (fig 3). A business unit is that level in the organisation where there is a clearly defined product with a discernible customer base. ${ }^{6}$ An emergency department has a clearly defined product-that is, emergency care-and patients who are the customers. A business unit is responsible for its operational procedures, resource management, expenditure, activities, performance, and bottom line.

We adopted this organisational structure as there had been discontent and discipline problems on the ground because of disagreements between the two heads. This was dangerous as "maintaining discipline and standards within an A\&E department are essential to its functioning. ${ }^{17}$

"Most people entering medicine and nursing do so with some belief that they will be able to help people... (i.e. they should be more internally driven by the desire to do a good job than need constant external monitoring ). ${ }^{\prime 8}$ This is generally true of emergency department staff but there will be occasions when monitoring and disciplinary actions are required. On these occasions, legitimate power and sometimes coercive power will have to be exercised. It is easier to do so within the structure of a business unit centre that operates under one head. 


\section{Box 2 SWOT analysis of the intermediate} organisational structure

\section{Strength}

- inputs from different views

- medical became a stakeholder in the growth of other groups

- multitasking is more acceptable

\section{Weakness}

- the point person reporting to the two bosses has a hard time whenever the two bosses disagree

- staff can "play" one boss against the other

\section{Opportunity}

- if synergy is present between the two bosses, the department can grow by leaps and bound as the resources available are multiplied

\section{Threat}

- the department can be pulled into different directions if the two bosses do not agree about goals

- energy and resources can be wasted

- "playing politics" wrecks havoc in any department

The medical staff were strongly in favour of the ED being run as a business unit centre but the nursing staff were less sure. It took time for them to adapt to a system where their "boss" was working with them in the department and not in an office far away. It took at least 12 months before they settled down to the new reporting structure. The nursing officers/supervisors had to be trained to respond to a different management style. As head of department, I spent a lot of structured time talking to the staff individually, explaining changes, my expectations of them, and the goals of the department.

I spent time identifying the opinion leaders among the staff. This is important as they may not be the most vocal but are the ones who can influence their peers to keep an open mind. When managing change, you have to accept the fact that not all will be won over at the same time and a few not at all.

Different styles were used when seeking the opinions of the various grades of staff and in explaining the changes to them. The age of the staff was also taken into consideration.

A staff strategic retreat was conducted on the first year that we became a business unit centre. During this retreat, it was explained to staff that as a business unit centre, we as a team were responsible for the emergency department's "bottom line". The reporting structure was explained-that is, the head of department was in charge of all grades of staff in the department.

One of the fads in hospitals is to run business unit centres. Should an A\&E clinical head of department take up the challenge-be responsible for the clinical, operational, and strategic positioning of the ED as well as its bottom line?

To quote, Machiavelli, "There is nothing more difficult to take in hand, more perilous to conduct or more uncertain in its success, than to take the lead in the introduction of a new order of things." Box 3 lists the SWOT analysis for the present organisational structure.

Most EDs in UK run on this model with the head of department (clinical director) responsible for the department. Heads of such EDs should ensure that there is no confusion about who controls the finances of the department. No one

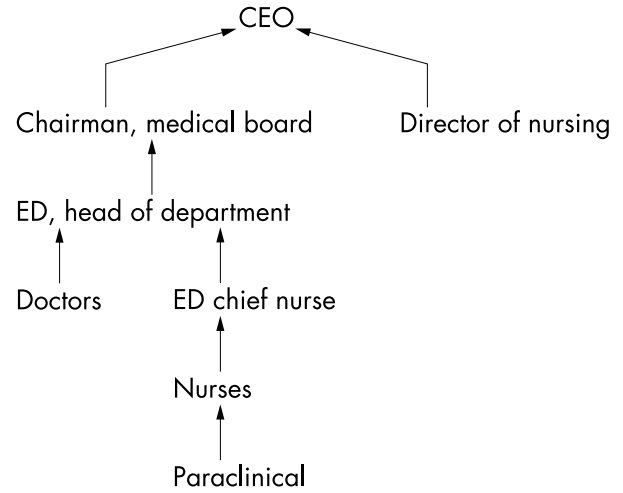

Figure 3 Present organisational structure (business unit centre).

should be able to siphon off any part of department's budget without the knowledge or consent of the department. The departmental head should not be held accountable for the department's bottom line if it is allowed to happen.

We are presently managing the crisis caused by severe acute respiratory syndrome (SARS). As our ED staff have worked in this organisational structure for almost two years, they had no problem in responding positively to a "command and control" mode required in a crisis. We have been able to manage the changes occurring daily because of a clear line of responsibility and command.

If we had been in a "silo" structure, it would have taken more than a week for the various heads to sort out their pecking order and for the staff to respond to it. The response would not have been as nimble or as positive.

An ED should avoid being divided into various services (for example, minor injury, resuscitation, primary care, observational medicine) with different heads. This would have a negative impact on the response of the ED in a crisis.

Our ED was able to respond and move swiftly as one because of the present organisational structure.

The senior management of the hospital may not be comfortable with this organisational structure if their relationships with the heads of department are less than cordial. There can be feelings of insecurity as they find it difficult to "control" a department that is the window or door to the hospital.

\section{Box 3 SWOT of the present organisational}

structure

\section{Strength}

- responsibility and accountability is clearly indicated

\section{Weakness}

- views and resources are limited

- dependent on department having a strong leadership

- the clinical head loses clinical work hours

\section{Opportunity}

- as goals are aligned, the ED is more nimble and can move faster

- the turnaround of projects is faster as decision making has less layers

Threat

- the department can stagnate 
A word of advice to those who are working towards this type of organisational structure, it is important to know the "movers and shakers" in your organisation ${ }^{5}$ and to develop a proactive approach rather than a reactive one towards hospital senior management. This will enable you to take control of your own (and department's) destiny. ${ }^{9}$

\section{MANAGING THE CHANGE}

Structure produces behaviour, and changing underlying structures can produce different patterns of behaviour. ${ }^{10}$

Change in the organisational structure is usually driven by a need to free the organisation from its present boundaries and improve its effectiveness. ${ }^{11}$

For change to work, people must be convinced that the change will be for the better of all. Time and effort are required.

Change works only if people go through transition. Change can take place very quickly but transition is on a different time scale. Transition can start even before change takes place.

Medical management must lead the way. They must be concerned and involve themselves with the development of ED nursing and operations even if they are not directly responsible. Generally, staff turn towards doctors for moral leadership even if they do not report directly to them. "Management is part of everyday accident and emergency (A\&E) consultant practice." ${ }^{4}$

"The first objective of any change is to define the objectives."11 This has to be communicated to the staff. The ED management must constantly communicate to guide staff through the process and improve trust. This should not only be to pass on information but to show care and to keep staff connected to the department, each other, and their work.
Change works only if it takes root in the hearts and minds of the organisation's people. ${ }^{11}$

\section{CONCLUSION}

Never in the field of healthcare provision has the pace of change been greater. ${ }^{12}$

ED management is expected to "thrive on chaos" while implementing change and ensuring the continued provision of care with as little disruption as possible. ${ }^{11}$

To paraphrase Jack Welch, change is an opportunity.

\section{ACKNOWLEDGEMENTS}

I would like to thank Professor Pete Driscoll for his advice on this article.

\section{REFERENCES}

1 Krames JA. The Welch way 24 lessons from the world's greatest CEO. New York: McGraw Hill, 2002.

2 Wardrope J, McCormick S. Team structure, waiting time and a psychotic patient is banging on your door. Emerg Med J 2001;18:382-5.

3 Wardrope J, McCormick S. Money, money, money. (Where does it come from, how do we control it, and how far should we go to get more?). Emerg Med J 2002; 19:146-8.

4 Robbins SP. Organisation behaviour, 6th edn. Englewood Cliffs, NJ: Prentice Hall, 1998.

5 Wardrope J, McCormick S. Introduction-St Jude's, the "virtual" A\&E department. Emerg Med J 2001;18:131-4.

6 Epelle AF. Business unit strategy. BusinessDAY News, 2003;3 Feb.

7 Wardrope J, McCormick S. Sex, drugs, and rock and roll. Emerg Med J 2002; 19:51-3

8 Wardrope J, McCormick S. Strategic decision making, motivation theory, and junior doctor interviews. Emerg Med J 2001;18:471-4.

9 Wardrope J, McCormick S. Strategy to every day operational management. Emerg Med J 2001;18:222-4

10 Senge PM. The fifth discipline. London: Random House, 1990.

$11 \mathrm{Na} \mathrm{BC}$. Change management in a changing landscape. Singapore: Institute of Public Administration and Management, 2002.

12 Wardrope J, McCormick S. Change, committees, and the press wants to speak to you. Emerg Med J 2002;19:333-6. 